\title{
THORAX
}

Editorials

\section{What role for theophylline?}

What role for theophylline today? After two decades of study and experience should we not be able to define the role of theophylline with almost "Hegelian" certainty? One can hear the retorts from the back benches. On a worldwide basis the use of theophylline remains substantial. In recent years, however, its role has been diminished, certainly by the emphasis on early institution of inhaled anti-inflammatory drugs, and now by the advent of inhaled long acting $\beta_{2}$ agonists. Inhaled corticosteroids do not eliminate entirely the need for bronchodilators, however, nor do they fully normalise airway responsiveness. ${ }^{1}$ Addition of long acting $\beta_{2}$ agonists reduces residual bronchospasm and improves nocturnal symptoms and sleep quality in most patients. ${ }^{2}$ This leaves us the task of redefining the role of theophylline by focusing on those properties of the drug that are still useful in certain clinical and economic circumstances.

\section{Sustained levels that can be tailored to meet the pattern of bronchospasms}

The constancy of action inherent in sustained release products remains an advantage of theophylline. As new $\beta_{2}$ agonists are introduced one can assume that market forces will lower the cost of conventional $\beta_{2}$ agonists so that many patients will continue to use them for economic reasons. Addition of theophylline to these agents blunts the recurring distress that signals the need for each new dose, reducing asthma symptoms and histamine reactivity. ${ }^{3}$ Nocturnal bronchospasm can be treated by a twice daily preparation of theophylline, if necessary skewing the dose to the night hours, or else using a once daily preparation in the evening. There are no detectable adverse effects on sleep quality ${ }^{4}$ even when studied in normal subjects. ${ }^{5}$ As generic forms of these older agents appear, it is entirely possible that the cost of such combined treatment will be substantially less than the cost of the new $\beta_{2}$ agonists.

\section{Additive bronchodilation to inhaled agents}

We have enough accumulated data, especially from studies in chronic obstructive pulmonary disease (COPD), to show that theophylline adds significantly to both peak and trough pulmonary function at usual doses of inhaled $\beta_{2}$ agonists, ${ }^{6-9}$ ipratropium bromide alone, ${ }^{10}$ or these two combined. ${ }^{11}$ In fact a surprising further reversibility can be shown in the patient with COPD or bronchitis when larger than conventional doses of $\beta_{2}$ agonists are combined with theophylline. In one study Barclay et al incrementally increased serum theophylline levels to their maximum response in forced vital capacity, or to a practical cutoff point. When $400 \mu \mathrm{g}$ salbutamol given by metered dose inhaler was then added, the final response was doubled. ${ }^{12}$
For most patients with chronic bronchitis $1400-3000 \mu \mathrm{g}$ was required to reach this maximum with salbutamol alone. ${ }^{13}$ Similar results were shown by Filuk et al. ${ }^{9}$ The presence of theophylline at adequate levels produces an optimal response to the inhaled agent. This may be simply by additive action, or the systemic agent may improve penetration of the inhaled agent - a view long held by Svedmyr and Svedmyr. ${ }^{14}$ The potential for overadditivity, or synergism, also exists, judging from in vitro studies with canine ${ }^{15}$ or guinea pig ${ }^{16}$ trachea. Proper consideration of the non-linearity of the bronchodilator response as its limits are approached has seldom been considered when comparing additivity with synergy. A strictly additive numerical result may actually indicate overadditivity when applied to a non-linear response curve.

\section{Systemic access}

Systemic access of bronchodilators becomes important in the asthmatic patient as small airways become plugged with secretions, necessitating mechanical ventilation in the extreme case. With our inability to judge whether inhaled $\beta_{2}$ agonists are actually penetrating the airways to reach their intended receptors, however, it is amazing that the systemic route is so frequently ignored. This situation would seem made to order for intravenous bronchodilators, whether aminophylline or $\beta_{2}$ agonists, certainly before reaching the point when the patient must be paralysed and sedated in order to reduce mean airway pressure.

There are few studies of methylxanthines in these patients. Fernandez et al showed that intravenous aminophylline was equally as effective as two puffs of salbutamol or ipratropium bromide when applied directly by special adaptor into the endotracheal tube, ${ }^{17}$ and Poggi et al showed a $30-40 \%$ reduction in lung resistance with intravenous doxophylline, a theophylline derivative, after correction for the contribution of the endotracheal tube. ${ }^{18}$ Most studies focus only on the peak response, but a study with inhaled fenoterol found a duration of action of only two hours, ${ }^{19}$ suggesting that application at this interval is necessary to maintain the benefit of inhaled $\beta_{2}$ agonists. Addition of aminophylline should add to and prolong the response. Strict guidelines for its administration must be observed, however, and serum levels monitored daily. ${ }^{2021}$ Patients should be otherwise stable since cardiovascular instability, pneumonia, and sepsis introduce unpredictable changes in theophylline pharmacokinetics. ${ }^{22}$

\section{Increase in respiratory muscle force}

This is a controversial area. The body of work, commencing with the studies of Aubier et al showing increased diaphragmatic force upon phrenic stimulation in young normal subjects, ${ }^{23}$ and ending with their large scale cross- 
over study of 60 patients with severe COPD, makes a compelling case. ${ }^{24}$ In the latter study they found an improvement in blood gases, tidal volumes, and maximum oesophageal pressure generated against an occluded airway. Other groups working with human subjects either support ${ }^{2526}$ or deny ${ }^{27-32}$ a significant effect on diaphragm contractility. It should be noted that this group used a mean theophylline level of $14.8 \mu \mathrm{g} / \mathrm{ml}$, essentially at the middle of the therapeutic range, to accomplish their results. ${ }^{24}$

An interesting aspect of the dose-response curves for theophylline in COPD is raised by the studies of Chrystyn et $a l^{33}$ and McKay et $a l^{34}$ which showed a progressive reduction of the "trapped gas volume" as theophylline levels moved up through the therapeutic range. The improvement in diaphragmatic position resulting from the decreased functional residual capacity and residual volume is likely to contribute to the increase in diaphragmatic force, tidal volume, exercise capacity, and symptomatic relief. An increase in the electrical activity of the diaphragm, which is a reflection of neural drive, does not seem to be the predominant factor at therapeutic levels. ${ }^{2635}$

No trials of the effect of aminophylline on weaning success in adults have been reported. A single case study showing considerable improvement of diaphragmatic force in a quadriplegic patient whose diaphragm was electrically paced is very difficult to explain on any other basis than an increase in diaphragmatic force of contraction. ${ }^{36}$

\section{Suppression of inflammation}

Several groups have shown significant suppression of the late phase response to antigen at modest serum levels of theophylline, proportionally more than its inhibition of the immediate phase, ${ }^{3738}$ and we are now back full circle into the phosphodiesterase (PDE) family in the search for a mechanism. Inhibition of the PDE III ("cGMP inhibited") and PDE IV ("cAMP specific") enzymes by various specific inhibitors produces smooth muscle relaxation, and specific inhibitors of PDE IV in the particulate fraction of granulocytes, and probably other cells, inhibit their activation and release of mediators. ${ }^{39}$ While theophylline is a non-specific PDE inhibitor, it has sufficient inhibitory activity at concentrations in the therapeutic range against extracts of these separated enzymes to be taken seriously when considering mechanisms of both muscle relaxation and suppression of inflammation, particularly in synergy with stimulants of adenylyl cyclase. ${ }^{40}$ Another intriguing area is the fact that theophylline, at nominal concentrations, strongly inhibits release of sensory neuropeptides in a guinea pig model. ${ }^{41}$ Whether these anti-inflammatory actions are significant in a clinical sense remains to be shown.

\section{Low cost and convenience}

"Non-scientific" considerations also figure in the equation. In countries without a universal health care system the cost of medications for asthma or COPD may consume a large part of a patient's pension. The advent of reliable generic preparations of slow release theophylline brings their cost down further (at my corner pharmacy only $\$ 8.00$ per month), making them the cheapest antiasthmatic medication in the United States. In some less developed countries this low cost and the convenience of the oral route are major advantages. One of our medical residents who had worked in the field in Nigeria stated that she "wouldn't have known how she could have managed without oral aminophylline." Worldwide distribution pat- terns for this drug can be explained partly by these considerations, as well as by the preference of some cultures for oral compounds.

\section{Negative factors}

The variable clearance, narrow therapeutic index, and severity of toxic reactions of theophylline necessitate close attention to dosing routines and subsequent monitoring; these represent the disadvantages of its use. Normal clearance rates of theophylline vary several fold, and this variation is increased by smoking, age, and interfering medications; the mean rate of clearance of theophylline in the elderly is reduced by $25 \%{ }^{42}$ If the effects of cardiac instability, liver disease, sepsis, sustained fever, and hypothyroidism are added, one naturally recoils. However, there are guidelines and measures which largely eliminate these disadvantages. The presence of, or a history of, recurring heart failure, overt liver disease, seizures, or cardiac arrhythmias are relative contraindications to the use of theophylline. With this mental checklist, a conservative dosing approach and monitoring of levels, together with education of the patient regarding those side effects which necessitate withdrawal of the drug (nausea, vomiting, headache, nervousness), theophylline can be safely prescribed. One usually begins with one half to two thirds of the initial full dose as an "adaptation phase." The initial full dose should be no more than $600 \mathrm{mg} /$ day in the adult, ${ }^{43}$ and serum levels should be monitored, preferably within a few days but possibly longer provided close contact between doctor and patient is maintained. The daily dose is then adjusted, usually with a twice daily preparation. If treatment is primarily to be directed to nocturnal symptoms, the dosing can be skewed or one of the once daily preparations can be administered in the evening.

\section{Potential for serious toxicity}

In the USA a lucrative legal practice has grown up around theophylline toxicity, including newspaper advertisements soliciting potential victims, and the exorbitant settlements that characterise the tort system. This is a sobering reality in the USA, and anyone using theophylline should be monitoring its levels and be aware of the major drug and host interactions. It is not surprising that its original popularity has declined. Dangerous scenarios include: (1) the use of prolonged intravenous infusions without daily monitoring of levels, particularly in the otherwise unstable patient; (2) polypharmacy under several physicians with its danger of duplicate prescribing of theophylline and interfering drug reactions; (3) prescription of theophylline in teaching institutions by inexperienced operators; (4) inadequately informed patients who are driven to use more of the "breathing drug;" and (5) unvolunteered over the counter sources of added theophylline. Suicidal attempts with this common and accessible drug have been reported, but a hospital with an organised approach to theophylline intoxication can manage such cases with a high degree of success. ${ }^{44}$ Concern for the effect of theophylline on behaviour, mood and cognitive processes in children seems to have settled into one of being on the alert for the occasional vulnerable child already experiencing problems. ${ }^{45}$ Early concerns appear to have been exaggerated.

\section{Clear indications}

Theophylline is clearly indicated in the following cases. (1) Patients with severe COPD who are dependent on 
bronchodilators and oxygen for any benefit. If they are adequately informed and closely followed, a trial of theophylline in the mid to slightly lower therapeutic range (12$15 \mu \mathrm{g} / \mathrm{ml}$ ) is important for those in whom dyspnoea gradually assumes total dominion over their lives. (2) Severe asthmatic patients in whom oral corticosteroids are being used or may be otherwise necessary. (3) Asthmatic patients with nocturnal symptoms, despite use of inhaled corticosteroids and the $\beta_{2}$ agonists available. (4) Patients with acute, severe asthma who are progressing into respiratory failure; this would include patients being mechanically ventilated, primarily for airway disorders, but who are otherwise stable. (5) Those socioeconomic systems where, through cost or non-availability, theophylline becomes the most feasible means of controlling airway obstruction.

\section{Contested areas}

At what point in the escalation of the severity of acute asthma is the addition of intravenous aminophylline warranted? There is still no agreement. National and international bodies agree that it should not be routinely used in the initial treatment of acute asthma since many studies have failed to show an advantage in the first three hours. Large doses of inhaled $\beta_{2}$ agonists and intravenous corticosteroids should be used first; those patients not responding, and those with life threatening features, are candidates for theophylline. ${ }^{2}$ Two recent studies in children in hospital were unable to show a significant advantage to the addition of aminophylline, ${ }^{4647}$ but Weinberger pointed out that both studies excluded from their protocol those patients with impending respiratory failure, not wishing to risk the use of placebo in these cases. ${ }^{48}$ Most would recommend its use in such patients. ${ }^{4950}$ In adults the results are conflicting. Self et al found no advantage to using aminophylline in 39 patients randomised to receive active drug or placebo, ${ }^{51}$ but Huang et al did find an advantage in the first few hours and point out a similar suggestive effect during the first eight hours in the study by Self et al as acknowledged by those authors. ${ }^{52}$ They suggest that aminophylline provides a "headstart" early in the course of treatment in the hospitalised patient. If so, the next question is how long it should be continued, since the risks of toxicity mount if the drug is not carefully monitored initially and daily. This entire issue thus remains unresolved.

A confounding study was published by Wrenn et al and prompted considerable interest. ${ }^{53} \mathrm{~A}$ total of 123 subjects with acute asthma were randomised to receive aminophylline or placebo, all receiving maximum treatment with the other agents. Despite any lack of difference whatsoever in the spirometric response (usually the basis used to compare regimens in the "negative" studies), only one third as many patients were deemed by independent observers to require admission in the group receiving aminophylline. McFadden speculated that aminophylline may have useful properties in this situation other than measurable bronchodilatation. ${ }^{54} \mathrm{~A}$ confirming study of this important issue is needed, since spirometry still fails to reflect this. ${ }^{55}$

Theophylline has recently been studied in sleep apnoea with the finding that the number of apnoeic and hypopnoeic episodes is reduced. ${ }^{56}$ The authors recommend its use in those patients in whom continuous positive airway pressure or surgery is either unacceptable to the patient or not indicated. This may become another indication.

In lesser grades of COPD and asthma the use of theophylline is in a "grey zone," subject to the preference of physician and patient, but certainly acceptable. Asthmatic children are often treated with theophylline for obvious practical reasons, and the current concerns about the effects of inhaled corticosteroids on growth rate may broaden its use.

Let me end with a musical analogy. Theophylline has been moved out of the first violin section into the viola or cello section where it selectively adds its own rich tones to the whole. It is definitely not playing second fiddle.

Division of Pulmonary and Critical Care,

Hines VA Hospital and Loyola University

JOHN W JENNE

Medical Center

Hines, Illinois 60141 ,

$U S A$

1 Woolcock A, Yan K, Salome CM. Effect of therapy on bronchial hyperresponsiveness in the long-term management of asthma. Clin Allergy 1988;18:165-76.

2 Fitzpatrick MF, Mackay T, Driver H, Douglas NJ. Salmeterol in nocturnal asthma: a double blind, placebo controlled trial of a long-acting inhaled $\beta_{2}$ agonist. $B M F$ 1990;301:1365-8.

3 Joad JP, Ahrens RC, Lindgren SC, Weinberger MW. Relative efficacy of maintenance therapy with theophylline, inhaled albuterol and the combination for chronic asthma. $\mathcal{F}$ Allergy Clin Immunol 1987;79:78-85.

4 Martin RJ, Cicutto LC, Ballard RD, Goldenheim PD, Cherniack RM. Circadian variation in theophylline concentrations and the treatment of nocturnal bronchospasm. Am Rev Respir Dis 1989;139:475-8.

5 Fitzpatrick MF, Engleman HM, Boellert F, McHardy R, Shapiro $\mathrm{CH}$, Deary IJ, et al. Effect of therapeutic theophylline levels on the sleep quality and daytime cognitive performance of normal subjects. Am Rev quality and daytime cognitive

6 Taylor DR, Buick B, Kinly C, Lowry RC, McDevitt DG. The efficacy of orally administered theophylline, inhaled salbutamol, and a combination of the two as chronic therapy in the management of chronic bronchitis with a reversible air flow obstruction. Am Rev Respir Dis 1985;131:74751.

7 Guyatt GH, Townsend M, Pugsley SO, Keller JL, Short HD, Taylor DW, et al. Bronchodilators in chronic air-flow limitation: effects on airway function, exercise capacity and quality of life. Am Rev Respir Dis function, exercise

8 Thomas P, Pugsley JA, Stewart JH. Theophylline and salbutamol improve pulmonary function in patients with irreversible chronic obstructive pulmonary disease. Chest 1992;101:160-5.

9 Filuk RB, Easton PA, Anthonisen NR. Response to large doses of salbutamol and theophylline in patients with chronic obstructive pulmonary disease. Am Rev Respir Dis 1985;132:871-4.

10 Bleeker ER, Johns M, Britt EJ. Greater bronchodilator effects of ipratropium compared to theophylline in chronic airflow obstruction. Chest 1988;94:3S.

11 Nishimura $\mathrm{K}$, Koyama $\mathrm{H}$, Izumi $\mathrm{T}$. Is oral theophylline effective in combination with both inhaled anti-cholinergic agents and inhaled $\beta_{2}-$
agonist in the treatment of stable COPD? Am Rev Respir Dis agonist in the

12 Barclay J, Whiting B, Merideth PA, Addis CW. Theophylline-salbutamol interaction. Bronchodilator responses to salbutamol at maximally effective plasma theophylline concentrations. $\mathrm{Br} \quad \mathcal{F}$ Clin Pharmocol 1981;11:203-8.

13 Barclay J, Whiting B, Addis CJ. The influence of theophylline on maximal response to salbutamol in severe chronic obstructive pulmonary disease. Eur 7 Clin Pharmacol 1982;22:389-93.

14 Svedmyr K, Svedmyr N. Does theophylline potentiate inhaled $\beta_{2}$-agonists? Allergy 1982;37:101-10.

15 Jenne JW, Yeoh HC, Shaughnessy TK, Hui K. Theophylline produces over-additive relaxation of canine tracheal smooth muscle when combined with beta-agonists: the dose-response relationship. Pulmonol Pharmacol 1992;5:239-49.

16 Persson CGA, Gustafsson B. Tracheal relaxation from combinations of xanthines and of a $\beta_{2}$-receptor agonist. Lung 1986;164:33-40.

17 Fernandez A, Lazaro A, Garcia A, Aragon C, Cerda E. Bronchodilators in patients with chronic obstructive pulmonary disease on mechanical ventilation. Utilization of metered dose inhalers. Am Rev Respir Dis 1990;141:164-8.

18 Poggi R, Brandolese R, Bernasconi M, Manzino E, Rossi A. Doxophylline and respiratory mechanics: short-term effects in mechanically ventilated patients with airflow obstruction and respiratory failure. Ches 1989;96:772-8.

19 Bernasconi M, Brandolese R, Poggi R, Manzino E, Rossi A. Dose-response effects and time course of effects of inhaled fenoterol on respiratory mechanics and arterial oxygen in mechanically ventilated patients with chronic airflow obstruction. Intensive Care Med 1990;16:108-14.

20 Westerfield BT, Carder AJ, Light RW. The relationship between arterial blood gases and serum theophylline clearance in critically ill patients. $\mathrm{Am}$ Rev Respir Dis 1981;124:17-20.

21 Zarowitz BJ, Pancarbo S, Dubey J, Wadenstorer F, Popovich J Jr. Variability in theophylline volume of distribution and clearance in patients with acute respiratory failure requiring mechanical ventilation. Chest 1988;93:381-5.

22 Powell JR, Voseh S, Hopewell P, Costello J, Sheiner LB, Riegelman S. Theophylline disposition in acutely ill hospitalized patients: the effect of smoking, heart failure, severe airway obstruction and pneumonia. Am Rev Respir Dis 1978;118:229-38.

23 Aubier MA, DeTroyer A, Sampson M, Macklem PT, Roussos C. Aminophylline improves diaphragmatic contractility. $N$ Engl $f$ Med 1981;305:249-52.

24 Murciano D, Auclair M-H, Pariente R, Aubier M. A randomized controlled trial of theophylline in patients with severe chronic obstructive pulmonary disease. $N$ Engl F Med 1989;320:1521-5.

25 Supinsky GS, Deal EC Jr, Kelson SG. The effects of caffeine and theophylline on diaphragm contractility. Am Rev Respir Dis theophylline on

26 Okubo S, Konno K, Ishizaki T, Kubo M, Suganuma T, Takizawa T. Effect of theophylline on respiratory neuromuscular drive. Eur $\mathcal{f}$ Clin Pharmacol 1987;33:85-8. 
27 Moxham J, Miller J. Wiles CM, Morris A Jr, Green M. Effect of aminophylline on the human diaphragm. Thorax 1985;40:288-92.

28 Kondragunta VR, Druz WS, Sharp JT. Dyspnea and diaphragmatic fatigue in patients with chronic obstructive pulmonary disease. Responses to theophylline. Am Rev Respir Dis 1988;137:662-7.

29 DeGarmo C, Cerny F, Conboy K, Ellis EF. In vivo effects of theophylline on diaphragm, bicep, and quadricep strength and fatiguability. $\mathcal{F}$ Allergy Clin Immunol 1988;82:1041-6.

30 Foxworthy JW, Reisz GR, Knudson SM, Cuddy PG, Pyszczynski DR, Emory CE. Theophylline and diaphragmatic contractility. Am Rev Respir Dis 1988;138:1532-4.

31 Javaheri S, Guerra L. Lung function, hypoxic and hypercapnic ventilatory responses, and respiratory muscle strength in normal subjects taking oral theophylline. Thorax 1990;45:743-7.

32 Swaminathan S, Paton JY, Davidson Ward SL, Sargent CW, Keens TG. Theophylline does not increase ventilatory responses to hypercapnea or hypoxia. Am Rev Respir Dis 1992;146:1398-401

33 Chrystyn H, Mulley BA, Peake MD. Dose response relation to oral theophylline in severe chronic obstructive airways disease. $B M \mathcal{F}$ 1988;297:1506-10.

34 McKay SE, Howie CA, Thomson AH, Whiting B, Addis GJ. Value of theophylline treatment in patients handicapped by chronic obstructive lung disease. Thorax 1993;48:227-32.

35 Murciano D, Aubier MA, Lecocquic Y, Pariente R. Effect of theophylline on diaphragmatic strength and fatigue in patients with chronic obstrucon diaphragmatic strength and fatigue in patients with

36 Nochomovitz ML, Hopkins M, Brodkey J, Montenegro H, Mortimer JT, Cherniack NS. Conditioning of the diaphragm with phrenic nerve stimulation after prolonged disuse. Am Rev Respir Dis 1984;130:685-8.

37 Pauwels R, Van Renterghem D, van der Straeten M, Johannesson N, Persson CGA. The effect of theophylline and enprophylline on allergeninduced bronchoconstriction. F Allergy Clin Immunol 1985.76.583-90.

38 Ward AJM, McKenniff M, Evans JM, Page CP, Costello JF. Theophylline - an immunomodulatory role in asthma? Am Rev Respir Dis 1993;147:518-23.

39 Torphy TJ, Undem BJ. Phosphodiesterase inhibitors: new opportunities for the treatment of asthma. Thorax 1991;46:512-23.

40 Nielson CP, Crowley JJ, Morgan ME, Vestal RE. Polymorphonuclear leukocyte inhibition by therapeutic concentrations is facilitated by cyclic$3^{\prime}, 5^{\prime}$ adenosine monophosphate. Am Rev Respir Dis 1988;137:25-30.

41 Barlinski J, Lockhard A, Frossard N. Modulation by theophylline and enprofylline of the excitatory non-cholinergic transmission in guinea-pig bronchi. Eur Respir f 1992;5:1201-5.
42 Vestal RE, Cusack BJ, Mercer GD. Aging and drug reactions. I. Effects of cimetidine and smoking on the oxidation of theophylline and cortisol in healthy men. I Pharmacol Exp Ther 1987;241:488-500.

43 Hendeles L, Weinberger M, Szefler SJ. Safety and efficacy of theophylline in children with asthma. $\mathcal{F}$ Pediatr 1992;120:177-83.

44 Parr MJ, Anaes FC, Day AC, Kletchko SL, Crone PD, Rankin APN Theophylline poisoning - a review of 64 cases. Intensize Care Med 1990;16:394-8.

45 Schlieper A, Alcock D, Beaudry P, Feldman W, Leikin L. Effect of therapeutic plasma concentrations of theophylline on behavior, cognitive processing and affect in children with asthma. 7 Pediatr 1991;118:449-55.

46 DiGiulio GA, Kercsmar CM, Krug SE, Alpert SE, Marx CM. Hospital treatment of asthma: lack of benefit from theophylline given in addition to nebulized albuterol and intravenously administered corticosteroid. 7 Pediatr 1993;122:464-9.

47 Carter E, Cruz M, Chesroun S, Shieh G, Reilly K, Hendeles L. Efficacy of intravenously administered theophylline in children hospitalized with severe asthma. F Pediatr 1993;122:470-6.

48 Weinberger $M$. Theophylline: when should it be used? $f$ Pediatr 1993;122:403-5.

49 British Thoracic Society. Guidelines on the management of asthma. Thorax 1993;48:S1-24.

50 National Asthma Education Program, Expert Panel on the Management of Asthma, National Heart, Lung and Blood Institute. Guidelines for the diagnosis and management of asthma. 7 Allergy Clin Immunol 1991;88:425-534

51 Self TH, Abou-Shala N, Burns R, Stewart CF, Ellis RF, Tsiv SJ, it al. Inhaled albuterol and oral prednisone therapy in hospitalized asthmatics. Does aminophylline add any benefit? Chest 1990;98:1317-21.

52 Huang D, O'Brien RG, Harmon E, Aull L, Reents S, Visser J, et al. Does aminophylline provide benefit for adults hospitalized with an acute exacerbation of asthma? Ann Intern Med 1993;119:1155-60.

53 Wrenn K, Slovis CM, Murphy F, Greenberg RS. Aminophylline therapy for acute bronchospastic disease in the emergency room. Ann Intern Med $1991 ; 115: 241-7$

54 McFadden ER Jr. Methylxanthines in the treatment of asthma: the rise, fall and the possible rise again. Ann Intern Med 1991;115:323-4.

55 Murphy DG, McDermott MF, Rydman RJ, Sloan EP, Zalenski RJ Aminophylline in the treatment of acute asthma when $\beta$,-adrenergics and steroids are provided. Arch Intern Med 1993;153:1784-8.

56 Mulloy E, McNicholas WT. Theophylline in obstructive sleep apnea. A double blind evaluation. Chest 1991;101:753-7. 